\title{
Núcleo de Estudos e Pesquisas em Educação de Jovens e Adultos - NEPEJA: uma experiência de interface extensão e pesquisa
}

\author{
Nágela Brandão ${ }^{1}$ \\ nagelabrandao@yahoo.com.br \\ Vânia Costa ${ }^{2}$ \\ vania.costa63@gmail.com \\ Márcia Nunes Monteiro ${ }^{3}$ \\ garanhuns@ig.com.br \\ Gilvanice Musial \\ gilvanicemusial@yahoo.com.br \\ Roberto Rezende ${ }^{5}$ \\ rob.rezende53@hotmail.com \\ Walquíria Rosa ${ }^{6}$ \\ wmrosa2032@yahoo.com.br
}

1 Doutora em Educação, professora da FaE/UEMG, integrante do NEPEJA.

3 Mestre em Educação, professora da FaE/UEMG, integrante do NEPEJA.

4 Doutora em Educação, professora da FaE/UEMG, integrante do NEPEJA.

5 Mestre em Educação, professor da FaE/UEMG, integrante do NEPEJA.

6 Doutoranda em Educação, professora da FaE/UEMG, integrante do NEPEJA. 


\section{Resumo}

As ações desenvolvidas pelo Núcleo de Estudos e Pesquisas em Educação de Jovens e Adultos da Faculdade de Educação da Universidade do Estado de Minas Gerais - NEPEJA/FaE/UEMG - têm possibilitado aos seus integrantes refletir acerca do papel social da universidade, em especial da extensão. Tais ações têm nos levado a indagar em que medida os sujeitos da sociedade civil, sobretudo dos movimentos sociais, têm sido incorporados no direito ao acesso e à criação cultural e às pesquisas científicas e tecnológicas produzidas no âmbito da universidade pública, não só como receptores, mas também como participantes e protagonistas. Este texto busca refletir sobre os desafios da indissociabilidade extensão-pesquisa-ensino a partir das experiências dos projetos desenvolvidos pelo NEPEJA e parceiros, sobretudo os projetos vinculados à Educação de Jovens e Adultos do campo. A noção de interface auxiliou na compreensão dos caminhos que o Núcleo vem trilhando nessa busca da indissociabilidade extensão-pesquisa-ensino.

Palavras-Chave: Educação de Jovens e Adultos (EJA); EJA do campo; extensão-pesquisa-ensino.

\section{Introdução}

A experiência do Núcleo de Estudos e Pesquisas em Educação de Jovens e Adultos (NEPEJA $)^{7}$ na gestão de projetos e na reflexão sobre a Educação de Jovens e Adultos (EJA), sobretudo a EJA do campo, tem incitado um conjunto de indagações sobre os limites e as potencialidades da sua atuação nessa área. Que desafios o Núcleo de Estudos e Pesquisas em Educação de Jovens e Adultos da Faculdade de Educação da UEMG se propõe a refletir em sua busca pela indissociabilidade extensão-ensino-pesquisa?

\footnotetext{
7 Agradecemos aos professores(as) vinculados(as) ao NEPEJA, que têm contribuído ao longo dos anos de existência do Núcleo com trabalhos e reflexões sobre o campo da Educação de Jovens e Adultos em suas diferentes interfaces com os movimentos sociais, educação do campo, educação e trabalho e história da educação das populações rurais, entre eles: Josemir Almeida Barros, Enelice Gomes Miconi, Lázaro Eustáquio da Silva Simin, Jussara Pinto Magalhães Penna, Ana Catharina Mesquita de Noronha. Agradecemos também aos alunos e alunas que integraram o Núcleo e aqueles que continuam inseridos nele, quer como bolsistas, quer como voluntários.
} 
Essa reflexão retoma um dos grandes debates no campo acadêmico quando se define a prática universitária pela indissociabilidade extensão-pesquisa-ensino. Esse debate, quando enfrentado a partir de uma concepção mais ampliada e alargada dessa prática, parte do pressuposto de que a indissociabilidade é um de seus princípios e, portanto, a ela inerente. Visto dessa forma, passaríamos a identificar as três atividades, mesmo que de forma desigual ou diferente, em toda prática universitária.

As críticas à universidade, e em especial à sua função social, recaem com maior intensidade quando em sua prática há prioridade ou ainda uma tendência para a desigualdade entre essas atividades ${ }^{8}$. Freire (1983), Chauí (2003), Santos (2005), entre outros têm debatido o compromisso social da universidade pública. Nesse debate e no discurso corrente, a indissociabilidade extensão-pesquisa-ensino, defendida como princípio da universidade, coloca-se mais como um devir, o que exige uma constante reflexão e busca.

Essas indagações têm sido objeto de reflexão no NEPEJA, principalmente pela sua trajetória que se inicia com questões provocadas pela extensão universitária. Dessa forma, entendemos que os desafios, objeto dessa reflexão, situam-se mais diretamente na interface extensão-pesquisa. Isso não significa o abandono do princípio da indissociabilidade, ao contrário, como perspectiva do fazer universitário, a noção de interface auxilia no clareamento dos caminhos que o Núcleo vem trilhando na busca desse princípio. Embora a indissociabilidade seja um princípio orientador das práticas, a interface se coloca como um caminho trilhado rumo a esse princípio. Para tanto, explorar os significados da palavra interface pode ser interessante como exercício reflexivo. No dicionário Houaiss (2004, p. 1.633), o verbete apresenta os seguintes significados, entre outros:

1. elemento que proporciona uma ligação física ou lógica entre dois sistemas ou parte de um sistema que não poderiam ser conectadas diretamente.

2. área em que coisas diversas (dois departamentos, duas ciências, etc.) interagem;

3. fronteira compartilhada por dois dispositivos,

8 Um exemplo forte de distinção entre as atividades pode ser identificado com a desproporção entre o financiamento da pesquisa e da extensão. 
sistemas ou programas que trocam dados e sinais; 4. superfície definida pela fronteira entre dois sistemas ou duas fases (HOUAISS, 2004, p. 1.633).

Percebemos que o verbete interface ${ }^{9}$ apresenta um leque de possibilidades que nos permite, neste momento, como processo de construção do fazer universitário, trazer para o debate termos como comuns, ligação, fronteira compartilhada, interação.

As ações desenvolvidas no âmbito da extensão têm possibilitado aos integrantes do NEPEJA refletir acerca do papel social da universidade e, em especial, da extensão. Assim, perguntamo-nos como tem se constituído historicamente as atribuições do ensino superior, bem como a relação universidade/sociedade. Tais ações têm nos levado a indagar em que medida os sujeitos da sociedade civil, sobretudo os movimentos sociais, têm sido incorporados no direito ao acesso e à criação cultural e às pesquisas científicas e tecnológicas produzidas no âmbito da universidade pública, não só como receptores, mas também como protagonistas? Tais questionamentos nos levam a refletir sobre as concepções de extensão adotadas pelas universidades e a necessidade de superar uma lógica de extensão cujos pressupostos sinalizam em direção a projetos assistencialistas visando a compensar a ausência do Estado com intenções puramente mercadológicas e esvaziada de qualquer sentido emancipatório.

É nessa direção que propomos as nossas reflexões acerca dos desafios do NEPEJA na busca pela indissociabilidade extensão-pesquisa-ensino a partir da análise da interface extensão-pesquisa nas experiências em seus projetos.

\section{O Núcleo de Educação de Jovens e Adultos - NEPEJA}

O Núcleo de Estudos e Pesquisas em Educação de Jovens e Adultos da Faculdade de Educação da Universidade do Estado de Minas Gerais - NEPEJA/FaE/UEMG - constituiu-se a partir da prática e da reflexão de um grupo professores e estudantes da Faculdade de Educação na atuação em diferentes espaços educativos nos quais a Educação de Jovens e Adultos se realiza. Isso tem possibilitado uma aproximação 9 A FAPEMIG tem um edital anual intitulado "A poio a projetos de extensão em interface com a pesquisa". 
das questões que envolvem as relações entre educação e trabalho, dos debates em torno da educação do campo (KOLLINGet al., 1999; ARROYO et al., 2004) e, mais recentemente, das questões inerentes à história da educação das populações rurais em Minas Gerais.

O envolvimento em diferentes atividades ao longo dos últimos doze $\operatorname{anos}^{10}$, tais como a inserção no Programa Nacional de Educação na Reforma Agrária - PRONERA ${ }^{11}$-, através do "Projeto educação, campo e consciência cidadã"12; a participação nas conferências estadual e nacionais de educação do campo e nos seminários de pesquisa em educação do campo ${ }^{13}$; a participação no Fórum Mineiro de Educação de Jovens e Adultos ${ }^{14}$; o diálogo iniciado com um grupo de educadores populares no âmbito da Grande $\mathrm{BH}^{15}$; a elaboração, em conjunto com educadores de jovens e adultos de acampamentos e assentamentos, de um material didáticopedagógico - Caderno do Educador - para a $\mathrm{EJA}^{16}$; o programa de estudos intitulado "Educação de jovens e adultos em áreas de reforma agrária em Minas Gerais"; os processos educativos gestados no "Projeto educação, campo e consciência cidadã"17; e a experiência recente no "Observatório

10 A experiência no desenvolvimento e na execução de atividades ligadas à EJA desde o ano 2000 levou à institucionalização do NEPEJA em julho de 2003.

11 No próximo tópico, trataremos do referido programa.

12 No próximo tópico, trataremos do referido projeto.

13 1997: Conferência estadual de Educação do Campo; 1998: I Conferência Nacional de Educação do Campo; II Conferência Nacional em Educação do Campo; 2005: I Encontro Nacional de Pesquisa em Educação do Campo; 2008: II Encontro Nacional de Pesquisa em Educação do Campo; 2010: III Encontro Nacional de Pesquisa em Educação do Campo.

14 Durante os anos de 2001 e 2002, a Faculdade de Educação secretariou o Fórum Mineiro de Educação de Jovens e Adultos e coordenou a realização do $4^{\circ}$ Encontro Nacional de Educação de Jovens e Adultos, em 2002.

15 No ano de 2002, tivemos a oportunidade de dialogar com um grupo de educadores que participavam do processo de consolidação de um projeto desenvolvido no bairro Palmital, na cidade de Santa Luzia, em Minas Gerais. O projeto se organizara a partir da constituição de uma rede de educadores populares nas cidades de Betim, Contagem e Ribeirão das Neves com o objetivo de atender a uma parcela da população de jovens e adultos excluída do ensino regular.

16 A primeira fase de elaboração desse material didático-pedagógico contou com o financiamento do Programa de Extensão (PROEXT), financiado pelo MEC, em 2007, e foi coordenado pelas professoras Márcia Helena Nunes Monteiro e Nágela Aparecida Brandão da FaE/UEMG.

17 O programa mencionado foi coordenado pela professora Lourdes Helena Silva (DPE/UFV), financiado pela FAPEMIG e teve como objetivos: a) Em relação ao conjunto dos parceiros envolvidos - Universidades, MST, FETAEMG e INCRA -, identificar suas avaliações sobre o projeto e analisar suas representações sociais sobre a dinâmica de gestão implementada; b) Em relação aos educadores(as), construir uma caracterização desses sujeitos e das práticas desenvolvidas no trabalho de alfabetização, de maneira a identificar, no processo de formação vivenciado por eles(as), os fatores explicativos da adoção de um determinado conceito de alfabetização e educação de jovens e adultos; c) Em relação aos educandos(as), descrever a trajetória dos assentados(as) envolvidos no projeto, de maneira a identificar tanto os impactos do processo de alfabetização em suas vidas sócio-profissionais, quanto analisar suas representações sociais sobre o projeto. 
da educação do campo" CAPES/INEP ${ }^{18}$; apresenta-nos elementos para pensar sobre as expectativas e os desafios colocados para o Núcleo no que se refere à construção de um trabalho coletivo, marcado pelos desafios constitutivos da indissociabilidade extensão-pesquisa-ensino.

Os resultados obtidos com os projetos acima citados, aliados às práticas, às reflexões e aos debates, têm contribuído para consolidar um conjunto de produções em torno da Educação de Jovens e Adultos, mais precisamente da EJA do campo. Essas produções têm revelado a existência de uma diversidade de processos e práticas educativas na realidade do campo que exigem repensar a concepção de EJA orientadora das práticas construídas em nossa sociedade, bem como sobre as relações entre universidade e sociedade nos anos iniciais do século XXI.

É importante ressaltar que essas reflexões são oriundas da interface extensão-pesquisa realizada ao longo desses anos, o que sinaliza em direção ao fortalecimento da articulação entre universidade e movimentos sociais de maneira dialógica. Temos pautado nossas ações pela lógica do trabalho coletivo, em que nossos parceiros (movimentos sociais, sindicais, educadores populares) possam conosco participar do processo de construção de novos conhecimentos.

Ao se originar de atividades eminentemente de extensão universitária, o NEPEJA não a tratou pelo viés da prestação de serviço, mas por uma concepção que caminha no sentido de superar a perspectiva de via de mão única, tão presente nos anos 80, nas universidades brasileiras (NETO, 1996). Assim, as experiências vividas no interior dos diferentes projetos têm nos permitido caminhar em direção a uma prática de extensão que supera a dimensão de transmissão de saber pela universidade, bem como considerar os diferentes saberes produzidos no cotidiano de vida e de trabalho de homens e mulheres como saberes válidos.

Nesse sentido, no interior do NEPEJA, considera-se que a produção

18 Aprovado no âmbito do Edital n ${ }^{\circ}$ 038/2010 - CAPES/INEP, o "Programa Observatório Educação do Campo: práticas em Educação de Jovens e Adultos, Letramento e Alternâncias Educativas" tem por objetivo congregar os grupos de pesquisas e extensão, pesquisadores e parceiros - movimentos sociais e sindicais do campo - e os programas de pós-graduação das três universidades públicas mineiras em torno de um trabalho articulado de pesquisa que visa a dar continuidade e avançar na sistematização e nos estudos que vêm sendo realizados em torno dos temas práticas de Educação de Jovens e Adultos, alfabetização e letramento e alternâncias educativas, de maneira a contribuir para o aprofundamento das reflexões e análises sobre as experiências de EJA na educação do campo. O referido projeto conta com a coordenação geral da Professora Lourdes Helena da Silva da DPE/UFV. 
do conhecimento, comprometido com os processos de transformação social, deve considerar a participação efetiva da comunidade, de forma interativa e coletiva. Nesse processo, os sujeitos contribuem com os processos de produção de conhecimentos que têm como ponto de partida a reflexão sobre sua realidade imediata.

Cabe ressaltar que a temática da educação do campo, nos últimos tempos, tem se consolidado nas produções acadêmicas e, principalmente, no cenário político nacional, com as lutas dos movimentos sociais, sindicais e tantos outros por políticas públicas de educação do campo.

Tais ações se coadunam com uma revisão profunda da concepção de universidade e de extensão. $\mathrm{O}$ papel da universidade assume um novo sentido a partir de sua inserção nas ações coletivas de formação humana desenvolvidas no âmbito dos movimentos sociais. Assim, a universidade passa a ser o espaço de discussões, de produção científica, tendo por base o trabalho coletivo, a partir do elo do compromisso social, na medida em que essa passa a ser participativa e coconstrutora dos saberes de novos modos de organização coletiva e de cidadania.

Assim, reconhecemos que a realidade da EJA do campo (RESENDE et al., 2011) é um tema ainda a ser mapeado, considerando a existência de uma diversidade de práticas e experiências dispersas no cotidiano do campo, captadas durante todos esses anos, e que demandam estudos mais específicos que se apresentam como novos desafios à universidade. Quais são eles? Para contribuir para esse debate, apresentamos em seguida a experiência do NEPEJA, em três de seus projetos.

\subsection{Projeto educação, campo e consciência cidadã}

O "Projeto educação, campo e consciência cidadã: $1^{\circ}$ segmento do Ensino Fundamental" foi desenvolvido no interior do PRONERA/ INCRA/MG desde 2001 e é coordenado pela Faculdade de Educação da Universidade do Estado de Minas Gerais.

O PRONERA ${ }^{19}$ é abalizado por princípios político-pedagógicos, nos

19 “ [...] a Educação do campo nasceu das demandas dos movimentos camponeses na construção de uma política educacional para os assentamentos de reforma agrária. Este é um fato extremamente relevante na compreensão da história da educação do campo. Dessa demanda também nasceu o Programa Nacional de Educação na Reforma Agrária (PRONERA)." (FERNANDES, 2005, p. 1-2). 
quais se articulam a inclusão de fundamentos teórico-metodológicos que ampliam as condições do acesso à educação como um direito social fundamental na construção da cidadania dos jovens e adultos que vivem nas áreas de reforma agrária; a indicação das demandas educacionais pelas comunidades das áreas de reforma agrária e suas organizações que, em conjunto com os demais parceiros, decidem sobre a elaboração, a execução e o acompanhamento dos projetos; a interação das ações desenvolvidas por meio de parcerias entre órgãos governamentais, instituições públicas de ensino e instituições comunitárias de ensino sem fins lucrativos, comunidades assentadas nas áreas de reforma agrária e as suas organizações; e a multiplicação que se relaciona à ampliação não só do número de pessoas alfabetizadas e formadas em diferentes níveis de ensino, mas também do número de educadores, de técnicos/agentes mobilizadores nas áreas de reforma agrária.

Esses princípios têm orientado a experiência do "Projeto educação, campo e consciência cidadã" ${ }^{20}$, que, de 2001 a 2012, desenvolveu quatro projetos $^{21}$. Os quatro projetos envolveram a alfabetização e a escolarização de jovens e adultos de assentamentos e acampamentos de reforma agrária de seis regiões de Minas Gerais - Triângulo Mineiro/Alto Paranaíba, Vale do Jequitinhonha, Mucuri, Vale do Rio Doce, Centro-Sul e Norte.

Ao longo desses anos, o projeto vem cumprindo três objetivos. $\mathrm{O}$ primeiro, a alfabetização e escolarização no $1^{\circ}$ segmento do Ensino Fundamental, incluindo a certificação referente a esse segmento. $\mathrm{O}$ segundo, a capacitação de educadores(as) através de ciclos de formação, oficinas e visitas às salas de aula. O terceiro, e, pontualmente, a certificação no $2^{\circ}$ segmento ${ }^{22}$ do Ensino Fundamental de jovens e adultos,

\footnotetext{
20 Ao longo dos projetos, construiu-se uma identidade para o trabalho que acabou sendo intitulado: "Projeto Educação, Campo e Consciência Cidadã". Todavia, cada um dos projetos teve um convênio específico, com metas próprias. Em 2005, o referido projeto ganhou o prêmio Medalha Paulo Freire, concedido pelo MEC. $21 \mathrm{O}$ primeiro projeto foi coordenado pela FAFIDIA/UEMG e os outros três pela FaE/UEMG. Têm sido parceiros mais permanentes ao longo desses dez anos, a Faculdade de Educação da Universidade do Estado de Minas Gerais, Departamento de Educação da Universidade Federal de Viçosa, Faculdade de Filosofia e Letras de Diamantina, Movimento dos Trabalhadores Rurais Sem Terra, Federação dos Trabalhadores Rurais da Agricultura do Estado de Minas Gerais. Em cada um dos convênios estiveram presentes fundações que fizeram a gestão financeira dos projetos (2000-2002: FEVALE; 2003-2004: FRAMINAS; 2004-2007: FUNARBE; 2007-2012: FUNDEP) pelas universidades e instituições de ensino superior e pelos movimentos sociais e sindicais parceiros.

$22 \mathrm{O} 2^{\circ}$ segmento se refere aos quatro últimos anos do Ensino Fundamental e foi desenvolvido na terceira versão do projeto (2004-2007).
} 
educadores(as) do projeto.

A experiência construída nos quatro projetos, relacionada à alfabetização e escolarização no primeiro segmento do Ensino Fundamental, tem provocado um conjunto de reflexões e, a partir disso, publicações (SILVA et al., 2007; SILVA, 2009; SILVA et al., 2010; ROSA et al., 2009; COSTA et al., 2010; BRANDÃO, MUSIAL, 2010; SILVA, COSTA, ROSA, 201123; entre outras) em torno do processo de formação dos educadores(as) envolvidos no projeto. As questões ali suscitadas foram sistematizadas em um programa de estudos intitulado "Educação de jovens e adultos em áreas de reforma agrária em Minas Gerais: os processos educativos gestados no Projeto educação, campo e consciência cidadã", coordenado pelo Departamento de Educação da Universidade Federal de Viçosa ${ }^{24}$, uma parceria fundada no diálogo e na ação coletiva em prol da construção do conhecimento.

Nesse sentido, um aspecto importante é a experiência de gestão e formação coletiva. Busca-se, nessa lógica, avançar na concepção, gestão e elaboração de um modelo de formação que visa a ampliar a mobilização dos envolvidos, aprofundar a discussão acerca dos eixos temáticos e elaborar conjuntamente a programação das atividades do projeto, afirmando o "Projeto educação, campo e consciência cidadã" como lócus formativo de todos os envolvidos na sua implementação, professores(as), alunos(as) universitários(as), educadores(as) de EJA das áreas de reforma agrária e lideranças dos movimentos sociais/sindicais parceiros. Assim sendo, o projeto contribui de maneira significativa para a emergência de um novo olhar para os sujeitos da EJA ${ }^{25}$, seus movimentos de luta, seus modos de vida e as formas de opressão social que vivenciam. Nesse sentido, as questões que afetam o cotidiano dos acampados e assentados e suas trajetórias de lutas no interior dos movimentos sociais se tornam também presentes no cotidiano das universidades públicas envolvidas.

A presença da sala de aula nos espaços de vida dos educandos(as),

23 Artigo recebeu $1^{\circ}$ lugar no Concurso Nacional de Artigos Científicos sobre Educação para a Diversidade, na área temática Alfabetização e Educação de Jovens e Adultos - ANPED/SECAD. 24 A Professora Lourdes Helena Silva (DPE/UFV) foi a coordenadora deste programa de pesquisas. 25 Para Arroyo (2005), esse novo olhar exige que se abandonem orientações supletivas e assistencialistas, de maneira a contribuir para que a Educação de Jovens de Adultos se efetive como uma política pública, como um dever do Estado. 
ou seja, nos assentamentos e acampamentos da reforma agrária provoca uma reflexão importante construída através das experiências do referido projeto (BARROS, AQUINO, SANTOS, 2010a; BARROS, AQUINO, SANTOS, 2010b). A garantia desse espaço/tempo, além de permitir o acesso e a realização dos processos educativos, materializa uma perspectiva de vida centrada na luta, na mobilização e na organização em prol de uma sociedade mais justa, fraterna, favorecendo, assim, o reconhecimento e a afirmação da identidade dos sujeitos assentados e acampados, bem como o fortalecimento das forças sociais ali existentes.

Arroyo (2005) insiste que é fundamental ampliar os olhares sobre os sujeitos da EJA, considerar não apenas suas trajetórias escolares truncadas, mas construir uma sensibilidade para suas trajetórias humanas, de vida, suas identidades coletivas de classe, gênero, raça, etnia. É preciso olhar para a trajetória perversa de exclusão social, de negação de direitos básicos à vida, ao trabalho e à sobrevivência. $\mathrm{O}$ autor aponta, ainda, para a necessidade de captar as trajetórias humanas na sua totalidade e as perceber como construtoras de percursos de socialização e sociabilidade, de busca de saberes, interrogação, tentativas de escolhas e formação de valores. As trajetórias escolares e humanas truncadas não significam a paralisação nos processos de formação mental, ética, identitária, cultural, social e política. Os jovens e adultos - homens e mulheres - trazem consigo um acúmulo de formação e aprendizagens que devem ser considerados no processo de escolarização desses sujeitos.

Em relação aos educadores(as), os resultados do programa de estudo revelam um conjunto das aprendizagens por eles(as) desenvolvidas nos diferentes tempos e espaços pedagógicos do projeto, do movimento social, assim como de outros espaços e/ou processos de escolarização formal. Cabe aqui ressaltar nessa direção o lugar ocupado pelas mulheres-educadoras que participam do projeto, que, em suas trajetórias como educadoras, refletem sistematicamente sobre suas histórias, suas condições de vida, suas escolhas e sobre os lugares que ocupam nos movimentos sociais.

Elas se veem envolvidas com o seu processo de formação e se mostram atentas aos seus processos de escolarização, bem como reconhecem a necessidade de continuidade dos estudos e da formação, e, para tal, 
empreendem ações objetivando a realização desses propósitos. Todavia, não deixam de reconhecer a existência de outros espaços significativos de aprendizagens para além dos processos de educação formal.

Pode-se afirmar que a prática pedagógica dos educadores no interior do referido projeto apresenta as seguintes especificidades: o trabalho é o tempo todo marcado pelas situações de sala de aula e vai sendo construído a partir dessas situações; embora os momentos de formação e acompanhamento pedagógico signifiquem muito no processo de formação dos educadores, é no cotidiano da sala de aula, sozinhos com os educandos, que os educadores constroem estratégias e redefinem as finalidades do trabalho; ao mesmo tempo em que interpretam e adaptam seus objetivos em função das situações concretas de trabalho, os educadores concebem e constroem meios para a realização dos objetivos.

Confirmou-se também a compreensão de que assentamentos e acampamentos ${ }^{26}$ de reforma agrária se configuram como espaços, territórios (FERNANDES, 2005) e organizações sociais diferenciadas, cujas especificidades se expressam nos desafios enfrentados pela EJA. Explicitam-se, assim, as tensões e as fronteiras da educação formal com a educação não formal própria da EJA, a própria ressignificação da concepção do que seja considerada uma aula que passa pela discussão e (re) definição, realizadas em conjunto pelos educandos(as) e educadores(as), sobre as aprendizagens envolvidas e os espaços de formação existentes no cotidiano de vida e de trabalho dos sujeitos da EJA. Dessa forma,

[...] conceber essas políticas impõe-nos desafios da produção de novos saberes inter-transdisciplinares, que sejam capazes de articular diferentes dimensões da vida dos sujeitos do campo, aliadas ao seu processo educacional, ou seja, uma escola colada ao chão da vida, ligada aos processos de produção da existência social desses sujeitos (MOLINA, 2008, p. 30).

\footnotetext{
26 O movimento social ocupa a terra devoluta ou improdutiva e ali as pessoas passam a viver em um acampamento que tem um sentido pedagógico de organização da vida em comum das famílias sem-terra debaixo das lonas, em situação de extrema precariedade material, mas de muita riqueza humana. É um espaço social de formação identitária de uma coletividade. Quando as terras são conquistadas pelo movimento social e, na perspectiva do Estado, a área é destinada a um conjunto de famílias sem-terra como forma de solucionar um problema fundiário, constitui-se um assentamento. Para o MST, o assentamento é um processo histórico de transição e transformação, de organização do território, do espaço agrário em questão. (CALDART, 2004).
} 
Deve-se ressaltar aqui a materialização de uma das diretrizes da extensão, qual seja o da bilateralidade, segundo o qual, há, conforme aponta Zedine (2011, p. 9), “[...] uma relação de reciprocidade, mutuamente transformadora, a partir da qual o saber científico se associa ao saber popular, a teoria à prática, onde se percebe um movimento dialético", mediatizado pela realidade concreta vivida pelos sujeitos em suas comunidades.

No interior do referido projeto, a universidade foi responsável pela formação dos educadores(as) e pelo acompanhamento das turmas de educação de jovens e adultos. A formação e o acompanhamento eram realizados em três formatos: visitas às turmas nos assentamentos $\mathrm{e}$ acampamentos de reforma agrária, oficinas em cada uma das regiões, e ciclos de formação em Belo Horizonte. O conjunto dessas atividades de formação e os processos reflexivos em torno dessas práticas, bem como a realização da pesquisa, já citada, que analisou os processos educativos gestados a partir dos diferentes parceiros envolvidos nos projetos de extensão desenvolvidos, evidenciaram, sobretudo, a importância da produção de um material didático-pedagógico para os(as) educadores(as). E é sobre essa experiência que nos debruçaremos no próximo tópico.

\subsection{Projeto elaboração de material didático-pedagógico para a educação de jovens e adultos: uma construção coletiva}

O "Projeto elaboração de material didático-pedagógico ${ }^{27}$ para a educação de jovens e adultos de acampamentos e assentamentos de reforma agrária", que deu origem ao "Caderno do educador", é resultado de uma demanda dos educadores e das educadoras que atuavam nas salas de aula dos assentamentos e acampamentos de reforma agrária de Minas Gerais.

O trabalho educativo desenvolvido nos assentamentos e acampamentos mostrou a capacidade e criatividade dos educadores e das educadoras. Mostrou ainda a necessidade de se criar um material didático adequado aos educandos, jovens e adultos, e ao seu contexto

27 Este projeto foi inicialmente financiado pelo PROEXT/MEC, em 2007. 
sociocultural. Considerando os educadores e as educadoras como autores de sua prática pedagógica, o projeto teve como objetivo geral elaborar um material com eles, a partir do trabalho que realizavam em sala de aula, e intensificar a formação como pesquisadores(as) da e com as comunidades das quais fazem parte.

Para a elaboração do "Caderno do educador", foi feita uma pesquisa com a intenção de se obter informações mais sistemáticas sobre a prática pedagógica desenvolvida nas turmas de educação de jovens e adultos. Em razão do objetivo do projeto, da realidade dos assentamentos e acampamentos, da sua localização de norte a sul de Minas Gerais e do número de educadores e educadoras (75), optou-se por uma metodologia de pesquisa que assegurasse, naquele momento (de 2005 a 2007), a participação de todos educadores e educadoras de forma direta ou representativa. Os educadores e as educadoras que fizeram parte do grupo representativo foram indicados pelos movimentos sociais e sindicais, pelos professores e pelos alunos universitários que atuavam com os educadores no "Projeto educação, campo e consciência cidadã: $1^{\circ}$ segmento do Ensino Fundamental".

A concepção metodológica que norteou o projeto se pautou em trabalhos que veem os educadores como coparticipantes da construção de projetos políticos-pedagógicos e do currículo. Nesse grupo se destacam Giroux (1997), Sacristan (1998), Nóvoa (1995), Perrenoud (1993) e Freire (no conjunto de sua obra). Giroux (1997) explicita a sua opção por encarar os professores como intelectuais, o que significa, segundo ele, fornecer uma "[...] vigorosa crítica teórica das ideologias tecnocráticas e instrumentais subjacentes à teoria educacional que separa a conceituação, planejamento e organização curricular dos processos de implementação e execução." (GIROUX, 1997, p. 161). A metodologia foi pautada em momentos inter-relacionados e, às vezes, simultâneos e que não podem ser vistos como etapas lineares.

No primeiro momento de elaboração desse material, como citado, foi feita uma pesquisa com todos os educadores e educadoras que participavam do projeto e que responderam a questões relativas ao seu trabalho: temas, conteúdos, atividades. No segundo momento, foi feita 
uma entrevista com roteiro previamente construído, com a intenção de identificar alguns elementos de suas práticas pedagógicas. As informações obtidas na pesquisa mais ampla e nas entrevistas foram organizadas e analisadas de modo que pudessem orientar a construção do material.

No terceiro momento, universidade (professores e alunos bolsistas) e movimentos sociais e sindicais passaram a identificar as experiências de sala de aula que iam ao encontro das temáticas indicadas na fase anterior da pesquisa. Cada experiência identificada foi registrada por um professor da universidade a partir de entrevista com o educador que a realizou e dos materiais que haviam sido produzidos. Dessa forma, as atividades selecionadas para o material didático-pedagógico, construídas pelos educadores e educadoras, foram relatadas, refletidas e teorizadas pelo professor universitário e reelaboradas por um grupo de doze educadores(as) com a participação de professores e alunos universitários. O resultado desse processo contou com a diagramação e editoração realizada por alunos estagiários da Escola de Design da UEMG e ficou denominado "Caderno do educador".

Esse caderno possui a seguinte sequência: o histórico do projeto e da pesquisa, um texto sobre Planejamento - relato oral feito por uma educadora do Movimento dos Trabalhadores Rurais Sem Terra de Minas Gerais (MST/MG) - e outro sobre O primeiro dia de aula - carta de uma educadora da Federação dos Trabalhadores na Agricultura do Estado de Minas Gerais (FETAEMG) -, ambos adaptados para esse caderno. Os temas e as atividades correspondentes a cada tema foram indicados pela pesquisa realizada com os educadores e as educadoras, e apresentados no caderno na seguinte ordem: Identidade, Reforma Agrária, Trabalho, Ofícios e Bilhetes, Meio Ambiente e Cooperação.

O trabalho e o investimento realizado na elaboração do caderno exigem uma nova etapa de investigação, de modo a identificar, refletir e analisar o processo de apropriação dos educadores e das educadoras desse material didático-pedagógico destinado à educação de jovens e adultos que vivem nos assentamentos e acampamentos de reforma agrária em pelo menos duas regiões de Minas Gerais. As reflexões a seguir dizem respeito a essa experiência. 


\section{Os modos de apropriação do material didático- -pedagógico por educadores de jovens e adultos de acampamentos e assentamentos de reforma agrária}

Buscando compreender, no campo da formação de educadores, como se dá o processo de apropriação de um material didáticopedagógico produzido com educadores de jovens e adultos foi elaborado o projeto "Educação do campo em construção: apropriação de material didático-pedagógico por educadores de jovens e adultos" ${ }^{28}$ Pautado pelos pressupostos teórico-metodológicos anteriormente explicitados, o projeto foi organizado em alguns momentos inter-relacionados: o primeiro momento foi destinado a instaurar o interesse e o envolvimento dos(as) educadores(as) para a participação no processo de uso e de reelaboração do material didático-pedagógico. Para tanto, organizou-se um seminário com a participação de educadoras de duas regiões de Minas Gerais, quais sejam Norte e Rio Doce ${ }^{29}$. O evento contou ainda com a presença de três educadores da educação básica ${ }^{30}$ e bolsistas de iniciação científica da FaE/UEMG que acompanham os trabalhos nas duas regiões que participam do projeto. Lideranças do MST e da FETAEMG também marcaram presença. A coordenação dos trabalhos foi realizada por professores da FaE/UEMG nos diferentes temas discutidos e analisados durante o dia de trabalho.

Os temas debatidos durante o seminário foram assim definidos: em um primeiro momento, apresentação do "Caderno do educador" e seu histórico, em seguida, apresentação do "Observatório da educação do campo" e do projeto de pesquisa em questão. Na sequência, foi discutida a metodologia de trabalho/pesquisa e construído, coletivamente, o

28 O referido projeto integra o "Observatório da Educação do Campo: educação de jovens e adultos, alternâncias educativas e letramento", financiado pela CAPES (2010-2012), tem a coordenação geral da Professora Lourdes Helena Silva, DPE/UFV e na FaE/UEMG é coordenado pela Professora Gilvanice Barbosa da Silva Musial. Conta ainda com a coordenação da professora Maria do Socorro Alencar Nunes Macedo, pela UFSJ. Essa proposta do Observatório é desenvolvida pelas três universidades que compõem um Núcleo em Rede, integrando os seus programas de pós-graduação em educação.

29 O referido seminário contou com a presença de três educadoras de salas de aula de educação de jovens e adultos das seguintes áreas: acampamento Eloy Ferreira do MST, em Engenheiro Navarro-MG, assentamentos Para Terra I e Betinho da FETAEMG, localizados em Bocaiúva-MG, todos da região Norte de Minas Gerais.

30 Dois representantes do MST (um da região Norte e outra do Rio Doce) e um da FETAEMG (região Norte). 
cronograma de trabalho para os meses de agosto a dezembro de 2011.

Os educadores de jovens e adultos de acampamentos e assentamentos receberam e analisaram o material didático-pedagógico e demonstraram grande interesse em trabalhar com ele nas suas salas de aula. Sendo assim, definiu-se que esses educadores de jovens e adultos utilizariam o material durante os meses de agosto de 2011 a junho de 2012 e fariam anotações diárias sobre o planejamento, o acontecimento (aula propriamente dita) e a avaliação do acontecimento. Na oportunidade, destacou-se que o primeiro ponto considerado pelos educadores é que o "Caderno do educador" é um instrumento que possibilita conhecer, entender mais sobre a educação de jovens e adultos do campo e, consequentemente, apresenta contribuições para o referido campo. Outro ponto destacou que a simbologia que envolve o material ajuda a construir um sentido no cotidiano da sala de aula. Entretanto, antes de tomarem o material, algumas questões são muito importantes: O que fazer com o material? O que fazer a partir do momento que tomam o material nas mãos? E por onde começar?

Nesse sentido, ressaltou-se que esse material não se destina à alfabetização especificamente, embora possa ser utilizado em alguns momentos dos processos de aquisição da leitura. Outra característica é o fato de o material não se constituir em livro de uso diário. Antes, constitui-se como um material de apoio ao educador de jovens e adultos no processo de ensino da leitura e da escrita, entendidas como práticas sociais, e está organizado por temas, em que cada um deles compreende um relato sucinto sobre a experiência que deu origem à referida unidade de estudo, texto de aprofundamento sobre o tema escolhido e as sugestões de atividades.

O segundo momento, já iniciado, refere-se ao mapeamento e descrição das práticas pedagógicas desenvolvidas nas turmas de educação de jovens e adultos. A observação e o registro estão sendo realizados por alunas universitárias - bolsistas de iniciação científica -, educadores da educação básica e educadoras da educação de jovens e adultos, que utilizarão o material durante os meses de agosto de 2011 a junho de 2012. Os registros serão realizados durante os onze meses em períodos contínuos de uma semana a cada dois meses para as bolsistas de iniciação 
científica, semanalmente para os educadores da educação básica e diariamente para as educadoras da EJA.

O terceiro momento compreenderá a análise dos usos e apropriações do material pelos(as) educadores(as). Nesse momento serão sistematizados os referenciais teóricos que orientam esse projeto. $\mathrm{O}$ resultado dessas análises orientará tanto a reformulação do material quanto a formação continuada de educadores da EJA que participarão de todo o processo. $\mathrm{O}$ quarto momento será específico para a reelaboração e formatação final do material didático-pedagógico. O projeto culminará com a realização de um seminário final envolvendo os participantes e outros interlocutores da comunidade e da sociedade diretamente relacionados à educação de jovens e adultos em um debate sobre a educação do campo.

\section{Considerações finais}

As análises das produções teóricas dos seminários e encontros de pesquisadores da educação do campo revelam que ainda são poucos os estudos que têm como foco as experiências de educação de jovens e adultos que se realizam no campo brasileiro.

Essa situação expressa a necessidade de um aprofundamento da interface educação do campo e educação de jovens e adultos, o que os projetos aqui apresentados têm se proposto e o fazem, colocando como foco central a formação de educadores e a produção de material didático-pedagógico para a educação de jovens e adultos do campo, de forma compartilhada com educadores e educadoras de áreas de reforma agrária de diferentes regiões de Minas Gerais.

Desse modo, tanto a formação de educadores e educadoras, como produção de material didático-pedagógico para educação de jovens e adultos adquirem novos significados na vida e no trabalho dos assentados e dos acampados rurais, como na própria ação da universidade, que pode ressignificar seu papel político e social nas parcerias com os movimentos sociais e sindicais do campo.

Dessa forma, as atividades do NEPEJA em torno dos projetos apresentados aqui possibilitam uma reflexão acerca da concepção de 
universidade e de extensão, bem como do desafio da indissociabilidade extensão-ensino-pesquisa. Isso nos leva a aprofundar os questionamentos e a indagar acerca da relação estabelecida com a produção do conhecimento e a relação que estabelecemos com os movimentos e os sujeitos sociais como coparticipantes dessa produção.

A concepção de extensão como prática construída com os sujeitos e não para (assistencialista) se evidencia na experiência realizada no interior dos projetos desenvolvidos pelo NEPEJA e parceiros, sobretudo os vinculados aos movimentos sindicais e sociais do campo. Assim, a gestão e a formação coletiva nos processos de organização e desenvolvimento do trabalho nos projetos em seus vários âmbitos, como, por exemplo, o planejamento e a execução coletiva dos ciclos e oficinas de formação de educadores, a produção de material didático, entre outros, afirmam uma visão de extensão como atividade emancipadora, como construção conjunta de conhecimentos e modos de intervenção na realidade e não política compensatória diante da ausência do Estado.

As ações desenvolvidas nos diferentes projetos remetem à reflexão sobre a necessidade de se ampliarem as discussões acerca das fronteiras entre os papéis de formação e as práticas educativas desenvolvidas pelos movimentos sociais e a universidade. Nesse sentido, aprendemos nessas ações que a produção do conhecimento tem como base a realidade concreta na qual estamos inseridos, movimentos sociais e universidade, como integrantes da sociedade civil.

A experiência de formação coletiva vivida e as produções teóricas delas decorrentes nos são colocadas como desafios: na interface entre extensão e pesquisa, a compreensão do significado da alfabetização na vida de jovens e adultos acampados e assentados rurais e maior clareza sobre os fatores que possibilitam a criação e a permanência de uma sala de aula em determinada comunidade, tendo em vista os índices de evasão na educação de jovens e adultos. Acreditamos que o aprofundamento da interlocução entre movimentos sociais e universidades visando à ampliação dos conhecimentos das diferentes e diversas práticas da EJA do campo e das possibilidades de intervenção coletiva nessas realidades contribuirá para o fortalecimento dessa interface. Na interface 
entre extensão e ensino, entendemos que, para além da formação de bolsistas de extensão e de pesquisa, nas questões tratadas no interior das experiências do NEPEJA, precisamos avançar na formação do pedagogo no interior do curso da FaE/UEMG, de modo que, para além da formação específica para educação infantil e séries iniciais, também possa formar educadores de jovens e adultos.

Finalmente, insistimos que o nosso desafio é a indissociabilidade extensão-pesquisa-ensino e que a análise na perspectiva da interface extensão-pesquisa se constitui um exercício analítico importante como parte do processo de construção do fazer universitário. 


\section{Referências}

ARROYO, M. G. Educação de Jovens e Adultos: um campo de direitos e responsabilidades públicas. IN: SOARES, L.; GIOVANETTI, M. A.; GOMES. N. L. Diálogos na educação de Jovens e Adultos. Belo Horizonte: Autêntica. 2005.

; CALDART, R. S.; MOLINA, M. C. Por uma Educação do Campo. Petrópolis, Vozes, 2004.

BARROS, J. A.; AQUINO, E. C. P. de; SANTOS, O. S. C. Movimentos sociais, políticas públicas e educação do campo. In: ENCONTRO NACIONAL DE PESQUISA EM EDUCAÇÃO DO CAMPO, 3., 2010a, Brasília. Anais... Brasília: Observatório de Educação no Campo, 2010a.

. Educação do Campo e EJA: reflexões a partir da extensão universitária. In: SEMINÁRIO SOBRE EDUCAÇÃO SUPERIOR E AS POLÍTICAS PARA O DESENVOLVIMENTO DO CAMPO BRASILEIRO, 3. ENCONTRO INTERNACIONAL DE EDUCAÇÃO DO CAMPO, 1, 2010b, Brasília. Anais... Brasília: Observatório de Educação no Campo, 2010b.

BOUMARD, P. L'école, les jeunes, la déviance. Paris: PUF, 1999.

BRANDÃO, N. A.; MUSIAL, G. B. S. Processo de trabalho do educador da EJA. In: ENCONTRO NACIONAL DE PESQUISA EM EDUCAÇÃO DO CAMPO, 3., SEMINÁRIO SOBRE EDUCAÇÃO SUPERIOR E AS POLÍTICAS PARA O DESENVOLVIMENTO DO CAMPO BRASILEIRO, 3., ENCONTRO, INTERNACIONAL DE EDUCAÇÃO DO CAMPO, 1., 2010b, Brasília. Anais... Disponível em: <http://www.encontroobservatorio.unb.br/arquivos/artigos/185>. Acesso em: 04 jun. 2011.

CALDART, R. S. Pedagogia do Movimento Sem Terra. Petrópolis: Vozes, 2004. 
CHAUÍ, M. A universidade pública sob nova perspectiva. Revista Brasileira de Educação, Rio de Janeiro, n. 24, p. 5-15, set./ dez., 2003.

COSTA, V. A.; ROSA, W. M. Trajetórias e Representações de Escrita de Educadoras de EJA. In: ENCONTRO NACIONAL DE DIDÁTICA E PRÁTICA DE ENSINO, 15., Belo Horizonte, 2010. Anais... Belo Horizonte: ENDIPE, 2010.

FERNANDES, B. M. Os campos da pesquisa em educação do campo: espaço e território como categorias essenciais. I Encontro Nacional de Pesquisa em Educação do Campo, Brasília, 2005. Disponível em: <http:// portal.mec.gov.br/secad/arquivos/pdf/educacaodocampo/ artigo_bernardo.pdf>. Acesso em: 04 jun. 2011

FREIRE, P. Comunicação ou Extensão? Rio de Janeiro, Paz e Terra, 1983.

- Que fazer: teoria e prática em educação popular. Rio de Janeiro: Vozes, 1989.

GIROUX, H. Os professores como intelectuais. Porto Alegre: Artemed, 1997.

KOLLING, E. J. et al. Por uma Educação básica do campo. Brasília: Fundação Universidade de Brasília, 1999

MAZZILLI, S. Associação entre ensino, pesquisa e extensão: influências do Movimento de Córdoba. In: CONGRESO ARGENTINO Y LATINOAMERICANO DE POSTGRADOS EN EDUCACIÓN SUPERIOR, 1., San Luis, Argentina, 2010. Anais... San Luis, Argentina: Universidad Nacional de San Luis, 2010.

MOLINA, M. C. A Constitucionalidade e a Justiciabilidade do direito à educação dos povos do campo. IN: SANTOS, C. A. (Org.) Por uma Educação do Campo. Campo, Políticas Públicas - Educação. Brasília: INCRA: MDA, 2008. 
NETO, J. F. de M. Extensão universitária e produção do conhecimento. Revista da ADUF/PB, n. 9, p. 13-17, jan./jun. 2003.

NOVOA, A. Os professores e sua formação. Lisboa: Dom Quixote, 1995.

PERRENOUD, P. Práticas pedagógicas, profissão docente e formação: perspectivas sociológicas. Lisboa: Dom Quixote, 1993.

RESENDE, R. M.; MUSIAL, G. B. S.; COSTA, V. A. Educação de jovens e adultos do campo. Presença Pedagógica, v. 17, p. 34-41, 2011.

ROSA, W. M.; COSTA, V. A. Educação de jovens e adultos em áreas de reforma agrária em Minas Gerais: representações de mulheres/ educadoras sobre a escrita. In: REUNIÃO DE ANTROPOLOGIA DO MERCOSUL, 8., 2009, Anais... Buenos Aires.

RUMMERT, S. M. A. A "marca social” da educação de jovens e adultos trabalhadores. In. SIMPÓSIO TRABALHO E EDUCAÇÃO, 4 ., 2007, Belo Horizonte, NETE/FAE/UFMG, v. 1, n. 4, ago. 2007.

SACRISTAN, J. G. Currículo: uma reflexão sobre a prática. Porto Alegre: Artmed, 1998.

SANTOS, B. de S. A universidade do século XXI: para uma reforma democrática e emancipatória da universidade. 2. ed. São Paulo: Cortez Editora, 2005. (Coleção questões de nossa época; v.120).

SILVA, L. H. et al. Projeto "Educação, campo e consciência cidadã" - avanços e perspectivas da formação de educadores na reforma agrária. In: CID, X. M.; PERES, A. (Org.). Educación social, animación sociocultural y desarrollo comunitario. Vigo: Universidade de Vigo, 2007, v. Tomo I, p. 227-236.

; COSTA, V. A.; ROSA, W. M. A educação de jovens e adultos em áreas de reforma agrária: desafios da formação de educadores do 
campo. Revista Brasileira de Educação, Rio de Janeiro, v. 16, n. 46, p. 149166, abr. 2011.

Projeto "Educação, campo e consciência cidadã": representações sociais e trajetórias de educandos do PRONERA. In: REUNIÃO ANUAL DA ANPED, 32., Caxambu, 2009. Anais... Caxambu: ANPEd.

. EJA em áreas de reforma agrária - representações, práticas e trajetórias de educandos do projeto “Educação, campo e consciência cidadã". In: CONGRESSO INTERNACIONAL DA CÁTEDRA UNESCO DE EDUCAÇÃO DE JOVENS E ADULTOS, 1., 2010, João Pessoa. Anais... João Pessoa, 2010. 


\title{
Center for Studies and Research Youth and Adult - NEPEJA: one extension interface experience and research
}

\begin{abstract}
The actions developed by the Nucleus of Studies and Researches in the Youth and Adults Education by the College of Education of the University of the State of Minas Gerais (NEPEJA/FaE/UEMG) have enabled its members to reflect upon the social role of the university, especially the role of extension. Such actions have made us wonder to what extent the civil society individuals, especially the ones from the social movements have been included in the rights of the access and cultural creation as well as the scientific and technological researches performed in the public university settings, not only as receptors but also as participants and protagonists. This text pursuits the reflection upon the challenges of the inseparableness of teaching, research and extension from the experiences of the projects developed by the NEPEJA and its partners, particularly the projects related to the education of the youth and adults of the rural areas. The notion of interface aided in the comprehension of the course of the action of the Nucleus in the aim of inseparableness of teaching, research and extension.

Keywords: Education of Youth and Adults (EJA); EJA of rural areas; teaching-research-extension.
\end{abstract}

Recebido: 14/09/11

Aprovado: 09/12/11 